\title{
LETTERS
}

\section{Acute myocardial infarction in young adults}

In the excellent case report and review by Osula et al, concerning acute myocardial infarction in young adults, commen was passed on the probable mechanism of the actual myocardial infarct described, and other possible causes were reviewed.'

The point made that the diagnosis of spontaneous coronary artery dissection is often made at postmortem is accepted. However in life myocardial infarction in the young, due to spontaneous coronary artery dissection, has been linked to both immunosuppression and hypertension..$^{2}$ There are a number of simila case series reported in the literature and it is clear from these that the survival rate is less good in the patients treated medically. ${ }^{4}$ It is also clear that thrombolytic therapy in spontaneous coronary artery dissection is poten tially a "double edged sword". Authors reporting the deterioration of patients after treatment with thrombolytics have suggested that thrombolytic induced bleeding into the dissected vessel wall is the probable cause of the clinical deterioration. ${ }^{56}$ Osula et al do suggest that diagnostic coronary angiography be performed in all cases but do not specify timing.

Early recognition of coronary artery angiographic abnormalities, including spontaneous dissection, is surely essential in the management of young patients with acute myocardial infarction. While recognis ing that the coronary arteries in this case were subsequently shown to be "normal", it could be argued that direct coronary angiography should precede (and potentially negate the need for) thrombolytic therapy in young patients with myocardial infarction.

\section{G Morgan-Hughes Cardiology Department South West Cardiothoracic Centre Plymouth NHS Trust, Plymouth, Devon PL6 8DH, UK; hughesgi@talk21.com}

\footnotetext{
References

1 Osula S, Bell G, Hornung R. Acute myocardial infarction in young adults: causes and management. Postgrad Med $J$ 2002;78:27-30

2 Tsimikas S, Giordano F, Tarazi R, et al. Spontaneous coronary artery dissection in patients with renal transplantation. Journal of Invasive Cardiology 1999;11:316-21.

3 Greenblatt J, Kochar G, Albornoz M. Multivessel spontaneous coronary artery dissection in a patient with severe systolic hypertension: a possible association. A case report. Angiology 1999;50:509-13

4 Prifti E, Bonachi M, Giunti G, et al. Coronary artery bypass grafting in patients with spontaneous coronary artery dissection. European Journal of Cardiovascular Intervention 1999;8:53-6.

5 Buys E, Suttorp M, Morshuis W, et al. Extension of spontaneous coronary artery dissection due to thrombolytic therapy. Cathet Cardiovasc Diagn 1994;33:157-60.
}

6 Zupan I, Noc M, Trinkaus D, et al. Double vessel extension of spontaneous left main coronary artery dissection in young women treated with thrombolytics. Catheterization and Cardiovascular Intervention 2001;52:226-30.

\section{Acute myocardial infarction in young adults}

The differential diagnosis of coronary embolism, acknowledged to be relevant to the aetiopathogenesis of myocardial infarction in the young, ${ }^{1}$ would be incomplete without mention of paradoxical coronary embolism, especially in the context of a diagnosis of nephrotic syndrome. As the authors themselves pointed out, severe hypoalbuminaemia is a risk factor for venous thrombosis, and the latter may, in turn, be complicated by embolic manifestations involving either the pulmonary or the systemic vascular bed. The latter, aptly entitled "paradoxical" embolism, may be more difficult to recognise when it occurs in the absence of concurrent pulmonary embolism, as in the 66 year old with patent foramen ovale, reported by Wiecking in $1971 .^{2}$ In the 24 year old reported by Jungbluth et al, the communication between the cardiac chambers was an atrial septal defect. ${ }^{3}$ According to the literature review undertaken by these authors, it is the association of pulmonary embolism (giving rise to an increase in right atrial pressure), and an interatrial communication which most commonly provides the pathophysiological "substrate" for this syndrome. Diagnostic difficulty may, however, be compounded by the fact that, even in the presence of clinically overt deep vein thrombosis, pulmonary embolism may, itself, be subclinical, ${ }^{4}$ with the possibility that the only clinically manifest embolic episode may be the one involving the coronary circulation.

O M P Jolobe Department of Adult Medicine Tameside General Hospital,

Fountain Street, Ashton under Lyne OL6 9RW, UK

\section{References}

1 Osula S, Bell GM, Hornung RS. Acute myocardial infarction in young adults: causes and management. Postgrad Med J 2002;78:27-30.

2 Wiecking DK. Paradoxical coronary embolism: report of a case. Am J Clin Pathol 1971;55:496-8.

3 Jungbluth A, Erbel R, Darius H, et al. Paradoxical coronary embolism: case report and review of the literature. Am Heart J 1988;116:879-84.

4 Nielsen HK, Husted SE, Krusell LR, et al. Silent pulmonary embolism in patients with deep venous thrombosis. Incidence and fate in a randomised, controlled trial of anticoagulation versus no anticoagulation. $J$ Intern Med 1994;235:457-61.

\section{BOOK REVIEWS}

The reviewers have been asked to rate these books in terms of four items: readability, how up to date they are, accuracy and reliability, and value for money, using simple four poin scales. From their opinions we have derived an overall "star" rating: * $=$ poor, ${ }^{* *}=$ reasonable, ${ }^{* * *}=$ good, ${ }^{* * * * *}=$ excellent

\section{Paediatric Radiology for MRCPCH and FRCR}

Edited by Christopher Schelvan, Annabel Copeman, Jane Young, Jacqueline Davis. (Pp $246 ; £ 17.50$.$) Royal Society of Medicine$ Press, 2002. ISBN 1-85315-466-0.***

This is another book in this series of books to aid candidates for the MRCPCH paediatric examination and it would also be useful for radiology trainees preparing for their exams in paediatrics.

The book is very clearly set out with a useful initial section of interpretation, rules, and tools with each of the 100 or so cases. There are clear answers and a useful list of radiology points and clinical relevant facts to the condition demonstrated.

There is a small bibliography of the books that could be referred to and it is unfortunate that the authors haven't referenced their radiology and paediatric points to the bibliography and/or other references. Nevertheless, the book will be a useful aid to doctors training for their examinations and, indeed, could be a useful text for CPD for consultants.

It is competitively priced at $£ 17.50$.

A C Elias-Jones

Consultant Paediatrician, Leicester Genera Hospital, Leicester, UK

\section{Comprehensive Care for People with Epilepsy.}

Edited by Margarete Pfäfflin, Robert T Fraser Rupprecht Thorbecke, Ulrich Specht, and Peter Wolf. (Pp 365; £60.) John Libbey, 2001. ISBN 0-86196-610-4.**

The 37 chapters of this book are derived from presentations that dealt with comprehensive care for epilepsy at a Bethel Cleveland Clinic Symposium (1999). Comprehensive care aims to incorporate the psychosocial aspects of disease to build "a framework for intervention and quality-of-life orientated outcome". The two opening chapters provide a succinct overview of international research in the area and convincingly demonstrate the importance of a comprehensive approach to epilepsy care.

Many of the proceeding chapters are descriptions of their authors' local programmes for various aspects of comprehensive care, for example, psychological treatment for seizure prevention or vocational rehabilitation. These may provide some stimulus to workers initiating similar endeavours. However, in many cases, the material is mainly descriptive with variable treatment of the background literature and 
limited assessment of efficacy, particularly in comparison to other approaches. I found the three chapterson the economics of epilepsy an excellent introduction to this field with clear explanations of the economic concepts and research methodology involved.

Most readers will probably find this book of limited interest. This is perhaps inevitable for a collection of presentations from a conference, particularly where the subject is so broad in scope and must draw from many disciplines. It may, however, have been useful to include a more substantial section drawing together the different strands of the comprehensive approach.

N F Moran

Specialist Registrar, Department of Neurology, St Thomas's Hospital, London, UK

\section{BOOKS RECEIVED}

The receipt of these books is acknowledged and this listing must be regarded as sufficient return for the courtesy of the sender. Books that appear to be of particular interest will be reviewed space permitted. The journal does not publish unsolicited reviews.

\section{The Specialist Registrar Handbook. 2nd Ed.}

By John Gatrell and Tony White. (Pp 324; price not quoted.) Radcliffe Medical Press, 2001. ISBN 1-85775-464-6.

Pass the MRCS Parts I and II All the Techniques You Need.

By Alison Walker, Chris Macklin, Christopher Williams. (Pp 120; £14.95.) Harcourt Health Sciences, 2001. ISBN 0-7020-2578-X.

\section{DIARY}

The Cell Biology of Reproduction

4-6 July 2002 (registration 3 July), St John's College, Cambridge, UK. The programme is aimed at scientists and clinicians with research interests and seeks to take understanding of the basic cellular biology of reproduction in the placenta, endometrium, and ovary and to translate this through into clinical problems. For further information contact the Congress Secretariat, PO Box 3219 Barnes, London SW13 9XR, UK (tel: +44 (0)20 8741 1311, fax: +44 (0)20 8741 0611, email: meetings@obgyn.cam.ac.uk).

\section{Techniques and Applications of} Molecular Biology: A Course for Medical Practitioners

8-11 July 2002, University of Warwick Coventry, UK. A four day residential course for those in the medical profession wishing to improve their understanding of the principles and applications of genetic engineering techniques. For further information contact $\mathrm{Dr}$ Charlotte Moonan, Department of Biological Sciences, University of Warwick, Coventry CV4 7AL, UK (tel: +44 (0)2476 523540 fax: +44 (0)2476 523701, email: Charlotte.

Moonan@warwick.ac.uk).

\section{An Introduction to \\ Bioinformatics: A Practical Approach}

2-3 September 2002, University of Warwick, Coventry, UK. A two day course for those wishing to gain a practical understanding of the applications of bioinformatics. For further information contact Dr Charlotte Moonan, Department of Biological Sciences, University of Warwick, Coventry CV4 7AL, UK (tel: +44 (0)2476 523540, fax: +44 (0)2476 523701, email: Charlotte.Moonan@warwick.ac.uk).

\section{Professional Updating in} Epidemiology. Design of Vaccination Programmes: From Sero-Epidemiology to Cost-Effectiveness

8-12 July 2002, University of Warwick Coventry, UK. The course intends to develop understanding of the epidemiological principles of vaccine programme design, including serological surveys, parameter estimation, transmission dynamic models, and costeffective analysis of different programmes. For further information contact Dr Stephen Hicks, Department of Biological Sciences University of Warwick, Coventry CV4 7AL, UK (tel: +44 (0)2476 523540, fax: +44 (0)2476 523701,email: s.j.hicks@warwick.ac.uk).

\section{Falk Symposium: GI}

Inflammation and Disturbed Gut Function: The Challenge of New Concepts

4-6 October 2002, Freiburg, Germany.

Falk Symposium: Targets for Treatment of IBD

6-8 October 2002, Freiburg, Germany.

Falk Symposium: Disease Progression and Carcinogenesis in the Gastrointestinal Tract

9-10 October 2002, Freiburg, Germany. For further information on the above contact the Falk Foundation eV, Congress Division, Leinenweberstr 5, PO Box 6529, D-7904 Freiburg, Germany (tel: +49 $761 \quad 15140$ fax: +49 761 1514359, email: symposia@ falkfoundation.de). 